\title{
Interactive comment on "Summertime
} observations of ultrafine particles and cloud condensation nuclei from the boundary layer to the free troposphere in the Arctic" by Julia Burkart et al.

Julia Burkart et al.

jburkart88@gmail.com

Received and published: 15 January 2017

The comment was uploaded in the form of a supplement:

http://www.atmos-chem-phys-discuss.net/acp-2016-701/acp-2016-701-AC3-

supplement.pdf 